\title{
O Movimento negro educador
}

Aline Batista de Paula'

GOMES, Nilma Lino. O movimento negro educador: saberes construídos nas lutas por emancipação. Petrópolis: Vozes, 2017.

Artigo recebido em março de 2021

Artigo aprovado em março de 2021

Desde os seus primórdios, o processo de luta e resistência dos escravizados foi atravessado pela construção de uma educação antirracista. Os quilombos são exemplos concretos disso, mais do que um lugar para abrigar e proteger escravizados fugidos, era um espaço importante do devir negro. As formas de organização do trabalho, línguas, religiões, tradições, ou seja, a cultura dos países africanos de origem, que foi brutalmente cerceada pelos colonizadores, assume extrema relevância. Os quilombos se organizam enquanto uma memória comunitária, um saber/fazer não hegemônico.

Os movimentos negros ${ }^{2}$ perpetuam essa característica de articulação da luta antirracista com a educação antirracista. Essa estratégia tem sido fundamental para o combate ao racismo, especialmente pelo processo de invisibilização social dos negros, que teve como base sua desumanização e sua consequente desqualificação. Nesse contexto, houve deturpações e apagamentos históricos de sua contribuição na sociedade brasileira. Esse movimento contribuiu de forma significativa para forjar o lugar dos negros - o trabalhador braçal, sem capacidade intelectual, com propensão à malandragem e ao crime, dentre outras características pejorativas, que impactaram no acesso e permanência na escola - seja porque faltava identificação com o material pedagógico, ou ainda pelo próprio racismo institucional. 
A educação (formal e informal) tem dois papéis fundamentais na sociedade, o primeiro refere-se à construção de conhecimentos e valores - visões de mundo, na produção do conhecimento, o bem e o mal, na estética, e diversos outros aspectos culturais e subjetivos; o segundo está relacionado a formação para o mercado de trabalho. Nesse sentido, o racismo perpetuado na educação tanto impacta na construção positiva de uma negritude, quanto dificulta o acesso à postos mais qualificados de trabalho, o que por sua vez impede que estabeleça sua renda e entrada nas demais políticas sociais (saúde, educação, habitação, transporte, dentre outras). Dessa forma, os eixos educação e trabalho sempre foram fundamentais para os movimentos negros.

Em seu livro O movimento negro educador - saberes construídos nas lutas por emancipação (2017), a professora Nilma Lino Gomes, coloca essa característica em foco. O texto faz um debate sobre os saberes produzidos e sistematizados pelos Movimentos negros, e de $\mathrm{Mu}$ Iheres negras, na sua capacidade de subversão da teoria construída na área educacional e de descolonizar o conhecimento. A fundamentação teórica de sua reflexão tem como base o pensamento de Boaventura Souza Santos através da pedagogia das ausências e das emergências. A autora evidencia os valores epistemológicos dos movimentos negros, enquanto produtores de determinada especificidade de conhecimento, que sintetiza a luta antirracista na sociedade brasileira, e como atores políticos que exercem pressão no Estado por políticas públicas de combate ao racismo.

Ao estabelecer a relação entre os Movimentos negros, educação e saberes, condiciona a sua compreensão nas tensões históricas de regulação-emancipação social que vão interferir na produção desses conhecimentos e saberes. Essas tensões se ancoram na construção de uma Ciência Moderna, de base eurocêntrica, como a única forma válida de conhecimento, atreladas à uma compreensão de direito diretamente vinculada ao direito estatal e de poderes sociais submetidos à política liberal. Essas reduções foram sendo reiteradas 
enquanto práticas sociais, acabando por se tornar, de acordo com Comes (2017) uma ortodoxia conceitual.

A autora retoma Santos (2002; 2004) para refletir sobre a tensão dialética que há entre essa relação regulação-emancipação, estabelecendo-a no paradigma da modernidade ocidental, que produz duas formas de conhecimento: o conhecimento-emancipação (que tem como produto a solidariedade) e o conhecimento-regulação (que tem como produto a ordem). Juntas essas duas formas de conhecimento tendem a produzir um equilíbrio dinâmico de retroalimentação. Todavia, no último século o conhecimento-regulação tem tomado a primazia, transformando a ordem na forma hegemônica do saber. Nessa perspectiva, o colonialismo passa a ser concebido enquanto ordem, considerando o sofrimento humano causado por esse processo nada mais do que um meio para alcançar a ordem. Qualquer tipo de solidariedade é concebido enquanto caos e a emancipação como outra forma de regulação, através de métodos rígidos, cânones e neutralidade.

Gomes (2017) ressalta a necessidade de reestabelecer o conhecimento-emancipação, valorizando tanto o conhecimento sistematizado na forma de teoria, quanto os saberes produzidos pela experiência prática. Assim sendo, a autora afırma que essa forma de conhecimento precisa ser contextualizada e localizada historicamente especialmente naquilo que Santos (2010) aponta como relação violenta entre norte e sul (colonizadores e colonizados), que produz um abismo no campo do conhecimento. Esse abismo só pode ser superado, a partir da quebra do paradigma da produção e apropriação do conhecimento a partir do ocidente hegemônico, ou seja, um conhecimento pós-abissal.

Destarte, os movimentos negros têm a possiblidade de serem protagonistas na construção de conhecimentos emancipatórios, considerando a sua postura inconformista e questionadora dos modelos hegemônicos estabelecidos. Para tal, Gomes (2017) salienta alguns saberes emancipatórios produzidos pela comunidade negra e sistematizados pelos movimentos negros brasileiros, com base na cons- 
trução de processos de produção e reprodução de existência dentro de uma sociedade profundamente racializada, que produzem uma determinada racionalidade.

Em primeiro lugar, a autora enfatiza os saberes identitários, através dos quais os movimentos negros recolocam o debate sobre raça no Brasil. Estabelece-se raça enquanto dimensão estruturante das relações sociais no Brasil e nos países colonizados, e colocam em xeque o mito da democracia racial. A pressão estabelecida em torno do conceito de raça, cria de acordo com Gomes (2017), uma nova visibilidade da questão racial e da identidade negra de maneira afırmativa, abrindo mais espaços para os movimentos negros na cena pública e política. Somando-se a isso, tanto o debate racial quanto os próprios militantes negros, que entram nas Universidades, e nos espaços de produção de conhecimento, gerando grande tensionamento.

Todavia, cabe ressaltar que a profusão do debate racial ao mesmo tempo em que auxilia na luta por dar visibilidade às expressões do racismo estrutural, pressionando não apenas o Estado, mas a sociedade, por mudança, também é utilizada como forma de esvaziamento político através do mercado, deturpando as demandas por transformações estruturais que impactariam nas condições reais de existência, por demandas apenas por consumo (produtos de beleza, roupas, turismo, etc.). Esse viés precisa ser acompanhado e combatido pelos movimentos negros.

Os saberes políticos são o segundo elemento apontados no livro, e o quanto os movimentos negros enquanto atores políticos foram essenciais para as mudanças em âmbito estatal. Seja através das contínuas e contundentes denúncias de racismo na sociedade brasileira, ou como consultores e pareceristas para promulgações de importantes leis. De acordo com Gomes (2017), a ressignificação do conceito de raça feita pelos movimentos negros passa a ser critério na adoção de políticas públicas como o Estatuto da Igualdade Racial (Lei 12.288/10), Lei de Cotas Sociorraciais nas Instituições Federais de Ensino (lei 12.711/12), a Ins- 
tituição da Obrigatoriedade do Ensino de História e Cultura Africana e Afro-Brasileira nas instituição do Ensino Básico (lei 10639/03), ou ainda a criação da Secretaria de Promoção da Igualdade Racial - SEPPIR.

Internamente os movimentos negros sempre formaram intelectuais, mas em 2000 fundaram a Associação Brasileiro de Pesquisadores Negros - ABPN, responsável pelo Congresso de Pesquisadores Negros - COPENE (que ocorre a cada dois anos), um espaço importante de socialização de pesquisas desenvolvidas sobre a temática racial no país. Nas universidades e faculdades, foram organizados os Núcleos de Estudos Afro Brasileiros - NEABs, responsáveis pela realização de pesquisas, extensão e formação, que tiveram respaldo da Secretaria de Educação Continuada- SECAD/MEC.

Gomes (2017) faz um destaque aos Movimentos de Mulheres Negras no seu trabalho de denunciar o machismo, o sexismo, a LgBTQ+ fobia na sociedade brasileira, e nos próprios movimentos negros, como também o extermínio da juventude negra e o feminicídio das mulheres negras. As mulheres negras têm nas últimas décadas conseguido alcançar, mesmo aquém do necessário, espaços públicos institucionais antes destinados apenas aos homens brancos, e dessa forma dar visibilidade às suas pautas. Como exemplo pode-se citar: a vereadora Marielle Franco - PSOL/RJ (que foi brutalmente assassinada em 2018, e o crime ainda não foi solucionado), as deputadas Talíria Petroni e Renata Souza (ambas do PSOL-RJ), ou ainda afro-transexual vereadora Erika Hilton - PSOL/SP, dentre outras.

Os saberes estético-corpóreos são os últimos saberes trazidos por Comes (2017), e o qual ela tece especial atenção. A autora coloca que apesar de serem os mais visíveis são os mais fáceis de serem transformados em não-existência. O mito da democracia racial têm sido um eficaz instrumento de invisibilização das desigualdades sociais e raciais, dando enfoque a o que a autora chama de um tipo "híbrido" que são mais aceitados socialmente (pele menos escura e cabelos menos crespo), um “corpo que se desloca do extremo negro 
para um extremo branco (p.78)". A branquidade é o padrão estético a ser desejado, pois também representa a característica moral a se alcançar. Como reflexo, há uma autorrejeição do corpo negro, e uma regulação na lógica da inferioridade racial.

Os movimentos negros também têm criado saberes que utilizam o corpo negro enquanto expressão de sua negritude, transgressão e emancipação. Como aponta Gomes (2017), esses saberes estéticos carregam resistências e luta por direitos. Ademais, há de se salientar que além de se colocar no embate nas relações de poder, a corporeidade negra é capaz de contribuir para a produção de uma nova ética, considerando que o corpo negro não se separa do sujeito coletivo. A identidade, apesar de aparentar uma individualidade, se constrói através das vivências e lutas coletivas, porque somos sujeitos históricos.

Esse corpo que foi escravizado e vilipendiado, também traz as marcas das histórias de lutas e resistências, todavia há um intenso controle sobre suas formas de expressão. No Brasil, segundo Gomes (2017), a história e cultura dos negros têm sido reguladas através do racismo, e principalmente através do mito da democracia racial. A escola tem exercido um importante papel nesse processo, ao criar e socializar um discurso formal que possibilitava fundamentar e perpetuar a regulação dos corpos negros. Por isso, ela tem sido alvo dos movimentos negros para a luta antirracista e pela emancipação do corpo negro, através de uma reinterpretação histórica, na qual as lacunas históricas fossem preenchidas com as lutas e resistências pela emancipação do seu corpo, ao invés de um corpo passivo e controlado.

Nessa relação tensão regulação-emancipação do corpo negro é importante ressaltar a questão da estética negra. O belo e o feio são uma construção social, são expressões de um processo histórico e político. Nesse sentido, em uma sociedade marcada pelo racismo, a estética também pode ser usada como forma de regulação e exclusão através da discriminação. Comes (2017) aponta que ao construir uma ideia de beleza-feiura hegemônicas pode se hierarquizar pessoas, gru- 
pos, raças e etnias. Na sociedade brasileira, esses padrões estéticos são brancos eurocêntricos e construídos no contexto do racismo. A cor da pele e a densidade do cabelo são utilizados para determinar a capacidade dos corpos negros.

Como estratégia emancipatória, os movimentos negros criaram a expressão beleza negra na tentativa de valorizar um padrão estético forjado no contexto do racismo. Por outro lado, como afirma a autora, o mercado de consumo se apropria dos símbolos da cultura afro-brasileira e os transforma em mercadoria esvaziando seu sentido político, mas que por outro lado também expressa um nível de mobilidade social. A entrada no mercado de consumo também foi utilizada para estabelecer pressões econômicas e jurídicas por parte dos movimentos negros. Era necessário atentar para as condições de boa parte da população negra que não conseguiam gozar de seus direitos básicos.

Gomes (2017) coloca que "o nível de pobreza dessa população não Ihe permite ser pensada e nem se pensar como público-consumidor" (p.113). Logo, tornava-se claro que as formas de combate à pobreza utilizadas, que desconsideravam as desigualdades raciais, até então não estavam sendo eficazes. Cresce então, as mobilizações pelas ações afırmativas de caráter racial visando o melhor acesso da população negra, principalmente, ao trabalho e a educação.

É fato que da primeira década até a metade da segunda dos anos 2000, muitas legislações de caráter afırmativo e valorativo voltados para os negros no Brasil foram implementadas. Mesmo não representando a totalidade das demandas apresentadas pelos movimentos negros, pode-se dizer que representam um grande avanço no que se refere a situação socioeconômica dos negros no país. Contudo, o impedimento da presidenta democraticamente eleita Dilma Housseff (2016), sem crime de responsabilidade, inaugurou um movimento de retrocesso de cunho antidemocrático. A priori, com o governo Temer (2016-2019) e posterior eleição de Jair Bolsonaro (2017) cria-se um cenário extremante adverso não apenas para o de- 
senvolvimento de quaisquer políticas de caráter afırmativo, mas para as políticas sociais como um todo. A agenda do governo Bolsonaro, alia ultraconservadorismo, neoliberalismo e dependência aos países de economia central, especialmente com os Estados Unidos, recrudescendo o desmonte das políticas sociais e o autoritarismo de base racista, sexista e LCBTQI+fóbica.

Essa nova conjuntura demanda novas estratégias para os movimentos negros na luta antirracista. Mesmo que a democracia não tenha chegado em sua totalidade à população pobre e negra do país, um formal Estado democrático de direitos permitiu, a partir das pressões exercidas pelos movimentos negros, uma certa ampliação dos direitos dos negros no país, todavia, nesse atual cenário de autoritarismo, o combate ao racismo no Brasil se torna mais árduo. Reiterando a necessidade de ampliação da articulação com diferentes movimentos sociais de diversas áreas.

Ao colocar o holofote nos saberes produzidos ao longo dos séculos pelos movimentos negros, Nilma Lino Gomes também nos aponta para quais as possibilidades e caminhos que podem ser seguidos. $O$ rico conhecimento produzido pode ser base para novas estratégias na luta antirracista.

\section{Notas}

1 Doutoranda do PPCSS/UERJ, bolsista da FAPERJ e professora substituta da Faculdade de Serviço Social/UERJ. E-mail: alinebpaula81@gmail.com. NºRCID 0000-0003-3399-6687.

2 A categoria Movimentos negros é utilizada no plural para ressaltar sua diversidade, heterogeneidade e contradições, como qualquer movimento social. Cabe destacar, que COMES (2017) apesar de utilizar a categoria no singular reforça as suas multiplicidades. Contudo, enquanto opção teórica utilizo no plural. 